\title{
Some Anthropometric and Motoric Performance Characterıstics of 10-14 Years Old Turkish Badminton Players
}

\section{0-14 Yaş Türk Badminton Oyuncularının Bazı Antropometrik ve Motorik Performans Özellikleri}

\author{
Beyhan Özgür \\ School of Physical Education and Sports, Mardin Artuklu University, Mardin, Turkey
}

B. Özgür

0000-0002-7813-4119

Geliş Tarihi/Date Received: 15.08.2019

Kabul Tarihi/Date Accepted: 27.10.2019

Yayın Tarihi/Published Online: 09.01.2020

Yazışma Adresi / Corresponding Author: Beyhan Özgür

Mardin Artuklu Üniversitesi Beden Eğitimi ve Spor Yüksekokulu, Mardin, Turkey E-mail:

beyhanozgur@artuklu.edu.tr

Objective: The goal of this study was to investigate anthropometric and motoric performance characteristics of Turkish badminton players of 10-14 age.

Material and Methods: A total of 166 male and 129 female badminton players from 35 different provinces participated in the study voluntarily. The research was conducted at U9, U11, U13 and U15 Turkish badminton championships. Height, stroke length, body weight measurements were taken; $20 \mathrm{~m}$ sprint, standing long jump, vertical jump, flexibility, medicine ball throwing and back strength tests were performed. Besides, anaerobic power and body mass index scores of the athletes were calculated. Mann Whitney- $U$ and independent samples t-test were used to compare differences between genders.

Results: Height, stroke length, body weight, body mass index, flexibility and anaerobic power of the 11-year-old female players were found to be significantly higher than those of males $(\mathrm{p}<0.05)$. The $20 \mathrm{~m}$ speed, standing long jump, vertical jump, medicine ball throwing and back strength data of 12, 13 and 14-year-old male players were significantly higher than their female counterparts $(p<0.05)$.

Conclusions: The fastest improvement in physical and motoric performance capacities of badminton players was observed at the age of 11 for females and at 1213 for males. For better performance development in badminton players, it is recommended to prepare specific training programs especially considering these rapid development stages.
\end{abstract}

Keywords: Badminton, anthropometry, motoric characteristics, performance

\section{öz}

Amaç: Bu çalışmada, 10-14 yaş Türk badminton oyuncularının antropometrik ve motorik performans özelliklerinin araştırılması amaçlandı.

Gereç ve Yöntem: Araştırmaya 35 farklı ilden 166 erkek ve 129 kız badmintoncu gönüllü olarak katıldı. Çalışma, U9, U11, U13 ve U15 Türkiye badminton şampiyonalarında yapıldı. Sporculara boy uzunluğu, kulaç uzunluğu, vücut ağırlığı ölçümleri, 20 m sürat, durarak uzun atlama, dikey sıçrama, esneklik, sağlık topu atma, sırt kuvveti testleri uygulandı. Ayrıca anaerobik güç ve beden kütle indeksi değerleri hesaplandı. Verilerin analizinde tanımlayıcı istatistikleri (ortalama ve standart sapma) kullanıldı. Cinsiyetler arasındaki farkı karşılaştırmak için Mann Whitney-U ve bağımsız grup t-testi uyguland.

Bulgular: Kız oyuncuların boy uzunluğu, kulaç uzunluğu, vücut ağırlığı, beden kütle indeksi, esneklik ve anaerobik güç değerleri 11 yaş grubunda erkeklerden anlamlı olarak yüksek bulundu ( $p<0.05)$. 12, 13 ve 14 yaşındaki erkek oyuncuların 20 m sürat, 
durarak uzun atlama, dikey sıçrama, sağlık topu atma ve sırt kuvveti verileri kızlardan anlamlı olarak yüksekti $(p<0.05)$.

Sonuç: Badmintoncuların antropometrik ve motorik performans kapasitelerinde en hızlı artışın olduğu dönem kızlarda 11, erkeklerde 12-13 yaşları olarak saptandı. Badmintoncularda daha iyi performans gelişimi için özellikle bu hızlı gelişim evrelerini dikkate alarak özgün antrenman programlarının hazırlanması önerilmektedir.

Anahtar Sözcükler: Badminton, antropometri, motorik özellik, performans

Available at: http://journalofsportsmedicine.org and http://dx.doi.org/10.5152/tjsm.2020.179

Cite this article as: Ozgur B. Some anthropometric and motoric performance characteristics of 10-14 years old Turkish badminton players. Turk J Sports Med. 2020;55(3):222-30.

\section{GíRiș}

Günümüzde elit sporcuların yüksek performansları birçok faktörün ortak etkisine bağlıdır (1). $\mathrm{Bu}$ faktörler, kalıtımsal, fizyolojik, fiziksel uygunluk, vücut kompozisyonu, teknik, taktik, biyomekanik, eğitim, sağlık durumu ve deneyim gibi unsurları kapsamaktadır. Üst düzey sporcuların fizyolojik ve fiziksel performans özellikleri spor branşına göre önemli ölçüde farklılık gösterir $(2,3)$. Bu nedenle, sporcular için en uygun antrenman stratejilerini geliştirmek amaciyla spor dalına özgü performans özelliklerini incelemek ve testler yapmak gerekir (4). Spor dalına uygun performans özelliklerinin belirlenmesi ve anlaşılması, sporcuların seçiminde, gelişiminde ve performans takibinde hedeflenen başarı için büyük katkı sağlamaktadır (2).

Üst düzey fiziksel performans gerektiren branşlardan biri de badmintondur. Badminton, oyuncuların ortasında file bulunan bir kortta raket ile kaz tüyünden yapılmış topa vurarak sayı kazanmaya çalıştığı olimpik bir spor dalıdır (5). Ayrıca, bu branş müsabakalar sırasında 400 $\mathrm{km} / \mathrm{s}$ 'i aşan tüytop hızı ile dünyanın en hızlı oynanan raket sporu olarak kabul edilmektedir (6). Ortalama olarak 40-50 dakika süren bir badminton maçında oyuncular farklı tekniklerle 500'den fazla vuruş gerçekleştirmekte olup, bu süreç içerisinde sporcuların esneklik, beceri, sürat, dayanıklılık ve koordinasyon özelliklerinin üst düzeyde olması gerekir (7). Badminton müsabakalarında rakibe üstünlük sağlayabilmek için kuvvet, güç, kas dayanıklılığı, esneklik, koordinasyon ve çeviklik gibi fiziksel özelliklerin yüksek seviyede olması oldukça önemlidir (8).

Son yıllarda, badminton branşı için yetenekli sporcu arayışında farklı yaklaşımlar olduğu görülmektedir. Örneğin; İngiltere, İskoçya, Kuzey
İrlanda ve Galler gibi Avrupa ülkeleri çocukların güç, kuvvet, hız, dayanıklılık, çeviklik, koordinasyon, esneklik, reaksiyon süresi, denge ve mental dayanıklılık gibi özelliklerine odaklanırken, Çin badminton yetenek yönlendirme programı ise spesifik olarak kemik taraması yoluyla öngörülen uzuv uzunluk ölçümleri, vücut şekli, boy ve somatotipler gibi antropometrik özelliklere önem vermektedir (9).

Badminton branşı ile ilgili ülkemizdeki çalışmalar incelendiğinde, araştırmacıların genellikle milli ve milli olmayan badmintoncuların fiziksel performans özelliklerini karşılaştırmaya yönelik çalışmalar yaptıkları görülmektedir (1012). Bazı araştırmacılar ise Türk ve yabancı milli takım oyuncularının fiziksel özelliklerini karşılaştırmıştır $(13,14)$. Bununla birlikte, badmintoncular ve farklı branşlardaki sporcuların performanslarını karşılaştıran çalışmalar da bulunmaktadır $(15,16)$.

Bugüne kadar özellikle alt yapı dönemindeki badminton oyuncularına yönelik Türkiye genelini kapsayan bir çalışma ele alınmamıştır. Yukarıda da ifade edildiği gibi araştırmalar genellikle üst yaş gruplarındaki milli oyuncuları incelemeye yönelik yapılmıştır. $\mathrm{Bu}$ nedenle, çalışmada 10-14 yaş Türk badminton oyuncularının antropometrik ve motorik performans özelliklerinin incelenmesi hedeflendi.

\section{GEREÇ ve YÖNTEM}

\section{Araştırma Grubu}

Araştırmaya, Türkiye genelinden 35 farklı ilden 166 erkek (10 yaş 17,11 yaş 40,12 yaş 53,13 yaş 30,14 yaş 26 ) ve $129 \mathrm{klz}$ ( 10 yaş 12,11 yaş 25,12 yaş 33,13 yaș 34,14 yaș 25 ) badminton oyuncusu katıldı. Çalışma, U9, U11, U13 ve U15 
Türkiye badminton şampiyonalarında yapıldı. Çalışmadan önce sporcu ve antrenörlere, çalışmanın başlığı, amacı ve yapılacak olan testler ile ilgili bilgilerin yer aldığı çalışmaya katılma onayl formu verildi ve kabul edenler araştırmaya dahil edildi. Ayrıca, çalışma Marmara Üniversitesi Sağlık Bilimleri Enstitüsü Klinik Araştırmalar Kurulu tarafından onaylandı (protokol no: 17.08.2010-10).

\section{Verilerin Toplanması}

Boy uzunluğu: Şerit metre duvara bant yardımıyla yapıştırıldı. Sporcular ayakkabısız bir şekilde topuklarını birleştirerek şerit metreye yaslandı. Sırt, kalça, başın arkası ve topuklar dikey skalaya yanaşarak dik bir şekilde durdular. Bu durumda cetvel başın en üst noktasına getirilerek, saçlar yeterli miktarda sıkıştırılarak ölçüm not edildi (17).

Kulaç uzunluğu: Katılımcının sırtı duvara yaslanmış şekilde kollar yere paralel olarak yanlara açıldı. İki kolun orta parmakları arasındaki mesafe şerit metre yardımıyla ölçüldü (17).

Vücut ağırlığı: Sinbo SBS-4414 marka ve $0.01 \mathrm{~kg}$ duyarlılıkta tartıda çıplak ayakla ölçüldü.

Beden kütle indeksi (BKI): Vücut ağırlığının boyun metre cinsinden karesine bölünmesiyle (vücut ağırlığı/ boy $^{2}$ ) elde edildi.

20 m sürat koşusu: Katılımcı tam olarak ölçülmüş başlangıç ve bitiş çizgileri belirgin 20 metrelik düz bir parkurda ayakta çıkış pozisyonu aldı. Hazır olduğunda başladı ve 20 metrelik parkuru en kısa sürede tamamlamaya çalıștı. Çıkış yapıldığında fotosel çalıștı ve bitiş bölgesine geldiklerinde fotosel otomatik olarak durdu. Katılımcılar iki kez koştular ve en iyi dereceleri not edildi. Koşular arası yeterli dinlenme verildi (17).

Durarak uzun atlama: Bu test alt ekstremite patlayıcı kuvvet değerlerini belirlemek için uygulandı. Düz bir zemine şerit metre yapıştırıldı ve sporcu çıkış çizgisinin gerisinde yerini aldı. Sporcunun ayak parmak uçları başlama çizgisinin gerisinde rahat bir duruş pozisyonundaydı. Komutla birlikte denek kol çekerek başlama çizgisinden ileri doğru mümkün olduğu kadar uza- ğa atlamaya çalıştı. Başlama çizgisiyle sporcunun bu çizgiye en yakın topuğu arasındaki mesafe skor olarak kaydedildi. İki deneme yapıldı ve en iyi derece not edildi (18).

Dikey sıçrama: Sporcunun orta parmağına duvarda iz bırakacak miktarda tebeşir sürüldü. Dik olarak sıçrama platformunun altında kolunun kaldırabileceği en yüksek noktaya dokunduruldu. Bu bölüm sıfır noktası olarak alındı. Sporcu dizleri hafifçe bükülü pozisyondan ani bir hareketle dikey olarak sıçrama yaparak platformda dokunabileceği en yüksek noktaya dokundu. İşaret bölümüyle sıçrama yüksekliği arasındaki mesafe sıçrama değeri olarak kaydedildi. Ölçüm iki kere yapıldı ve en iyi derece not edildi (17).

Esneklik (derin eğilme): Ölçüm yapılacak sporcu $50 \mathrm{~cm}$ yüksekliğinde bir basamak üzerine çıkarıldı. Basamağın kenarında ayakuçları basamağı geçmeyecek şekilde durdu. Bacakları bitişik olarak dizlerini bükmeden öne doğru eğildi. Parmaklarıyla dokunabildiği en alt nokta not edildi (17).

Sağlık topu firlatma: Üst ekstremite patlayıcı kuvvet değerini belirlemek için uygulandı. Spor$\mathrm{cu}$ başlama çizgisinin hemen gerisinde ve bir adım önde olmak üzere pozisyonunu aldı. $2 \mathrm{~kg}$ ağırlığındaki sağlık topunu baş üstünden her iki eliyle birlikte durduğu yerden mümkün olduğu kadar uzağa atmaya çalıștı. Yapılan iki deneme sonunda elde edilen en iyi derece kaydedildi (18).

Sırt kuvveti: Katılımcı sırtı düz, başı dik ve dizleri gergin olarak dinamometre platformunun üzerine çıtıtı. Geriye bükülmeksizin sırt kaslarını kullanarak tutamağı yukarıya doğru tüm kuvvetiyle çekti. Hareket öncesinde başı dik olacak şekilde gövdesini hafif olarak fleksiyona getirdi. İki deneme sonucunda en iyi derecesi skor olarak kaydedildi (19).

Anaerobik güç: Sporcuların anaerobik güçleri dikey sıçrama mesafesi ve vücut ağırlığından yararlanarak Lewis formülü ile (kg-m/s) cinsinden hesaplandı: $\left(\mathrm{P}=\sqrt{4} 4.9 *\right.$ Beden A $\left.\breve{g} ı r l ı \breve{g}_{\imath} * \sqrt{D}\right)$ (18). 


\section{Verilerin Analizi}

Veri analizinde katılımcıların tanımlayıcı istatistikleri (ortalama ve standart sapma) hesapland. Verilerin normal dağılım gösterip göstermediğini belirlemek için Shapiro-Wilk-W testi kullanılmıştır. Bu test sonucuna göre 10 yaş grubunda boy uzunluğu ve sağlık topu atma, 11 yaş grubunda ise boy uzunluğu ve beden kütle indeksi verilerinin normal dağılıma sahip olmadığı görülürken, diğer tüm verilerin normal dağılıma sahip olduğu bulundu. Cinsiyetler arasındaki farkı karşılaştırmak için normal dağılım göstermeyen veriler Mann Whitney-U, normal dağılıma sahip veriler ise bağımsız grup t-test kullanılarak analiz edildi.

\section{BULGULAR}

Erkekler 10 yaş grubunun 20 m sürat $(\mathrm{p}=0.001)$ ve dikey sıçrama $(p=0.017)$ verileri aynı yaş grubu kızlarınkinden anlamlı olarak yüksekti (Tablo 1). Kızlar 11 yaş grubunda boy uzunluğu $(p=0.001)$, kulaç uzunluğu $(p=0.002)$, vücut ağırlığı $(p=0.001)$, beden kütle indeksi $(p=0.007)$, esneklik ( $p=0.019)$ ve anaerobik güç $(\mathrm{p}=0.001)$ değerleri aynı yaş erkeklerden anlamlı olarak yüksek çıkarken, erkeklerin ise 20 $m$ sürat $(p=0.002)$ ve durarak uzun atlama $(p=0.028)$ değerleri kızlardan anlamlı düzeyde yüksekti (Tablo 2). Erkekler 12 yaş grubunda 20 $m$ sürat $(p=0.001)$, durarak uzun atlama $(p=0.001)$, dikey sıçrama $(p=0.005)$, sağlı topu atma $(p=0.001)$ ve sirt kuvveti $(p=0.001)$ verileri kızlardan anlamlı olarak yüksekti (Tablo 3). Aynı şekilde 13 yaş grubunda erkeklerin $20 \mathrm{~m}$ sürat $(p=0.001)$, durarak uzun atlama $(p=0.017)$, dikey sıçrama $(p=0.002)$, sağlık topu atma $(\mathrm{p}=0.004)$ ve sirt kuvveti $(\mathrm{p}=0.013)$ değerleri kızlardan anlamlı olarak yüksek çıkarken, kızların esneklik $(\mathrm{p}=0.011)$ değerleri erkeklerden anlamlı düzeyde yüksekti (Tablo 4). Erkekler 14 yaş grubunda da $20 \mathrm{~m}$ sürat $(\mathrm{p}=0.001)$, durarak uzun atlama $(\mathrm{p}=0.001)$, dikey sıçrama $(\mathrm{p}=0.011)$, sağllk topu atma $(\mathrm{p}=0.003)$ ve sirt kuvveti $(\mathrm{p}=0.001)$ verileri kızlardan anlamlı olarak yüksek çıkarken, kızların beden kütle indeksi $(p=0.008)$ değerleri erkeklerden anlamlı olarak yüksekti (Tablo 5).

Tablo 1. 10 yaș Türk badmintoncuların antropometrik ve motorik performans özellikleri

\begin{tabular}{|c|c|c|c|}
\hline Parametreler & Erkek $(n=17)$ & $\mathbf{K} \mathbf{1 z}(\mathrm{n}=12)$ & $\mathbf{p}$ \\
\hline Boy uzunluğu (cm) & $137.5 \pm 5.1$ & $137.1 \pm 8.0$ & 0.641 \\
\hline Kulaç uzunluğu (cm) & $137.4 \pm 6.0$ & $136.8 \pm 7.8$ & 0.797 \\
\hline Vücut ağırlığı (kg) & $30.5 \pm 3.5$ & $35.3 \pm 1.5$ & 0.740 \\
\hline BKİ (kg/boy $\left.{ }^{2}\right)$ & $16.1 \pm 1.3$ & $16.4 \pm 1.5$ & 0.527 \\
\hline 20 m sürat $(s)$ & $4.09 \pm 0.16$ & $4.39 \pm 0.21$ & $0.001 *$ \\
\hline Durarak uzun atlama $(\mathrm{cm})$ & $137.4 \pm 17.0$ & $125.8 \pm 15.2$ & 0.068 \\
\hline Dikey sıçrama (cm) & $26.8 \pm 3.2$ & $23.4 \pm 4.1$ & $0.017^{*}$ \\
\hline Esneklik (cm) & $5.06 \pm 5.33$ & $2.58 \pm 2.46$ & 0.147 \\
\hline Sağlık topu atma $(\mathrm{cm})$ & $330.7 \pm 65.9$ & $301.9 \pm 37.1$ & 0.330 \\
\hline Sirt kuvveti (kg) & $47.5 \pm 10.4$ & $41.0 \pm 9.5$ & 0.097 \\
\hline Anaerobik güç (kg-m/s) & $34.9 \pm 4.8$ & $33.1 \pm 6.0$ & 0.378 \\
\hline
\end{tabular}

BKİ: beden kütle indeksi, *: $p<0.05$ 
Tablo 2.11 yaş Türk badmintoncuların antropometrik ve motorik performans özellikleri

\begin{tabular}{llll}
\hline Parametreler & Erkek $(\mathrm{n}=40)$ & Kiz $(\mathrm{n}=25)$ & $\mathbf{p}$ \\
\hline Boy uzunluğu $(\mathrm{cm})$ & $142.9 \pm 6.5$ & $148.4 \pm 6.0$ & $\mathbf{0 . 0 0 1}$ \\
\hline Kulaç uzunluğu $(\mathrm{cm})$ & $144.1 \pm 6.3$ & $149.7 \pm 7.3$ & $\mathbf{0 . 0 0 2}^{*}$ \\
Vücut ağırlığı $(\mathrm{kg})_{\text {BKİ }\left(\mathrm{kg} / \text { boy }^{2}\right)}$ & $34.8 \pm 5.1$ & $42.3 \pm 9.1$ & $\mathbf{0 . 0 0 1}^{*}$ \\
20 m sürat $(\mathrm{s})$ & $17.0 \pm 1.7$ & $19.1 \pm 3.2$ & $\mathbf{0 . 0 0 7}^{*}$ \\
Durarak uzun atlama $(\mathrm{cm})$ & $4.06 \pm 0.23$ & $4.29 \pm 0.34$ & $\mathbf{0 . 0 0 2}^{*}$ \\
Dikey sıçrama $(\mathrm{cm})$ & $139.4 \pm 18.4$ & $128.6 \pm 19.8$ & $\mathbf{0 . 0 2 8}^{*}$ \\
Esneklik $(\mathrm{cm})$ & $26.2 \pm 5.7$ & $25.2 \pm 3.2$ & 0.356 \\
Sağlık topu atma $(\mathrm{cm})$ & $1.28 \pm 5.02$ & $4.80 \pm 6.71$ & $\mathbf{0 . 0 1 9}$ \\
Sırt kuvveti $(\mathrm{kg})$ & $389.1 \pm 73.7$ & $381.4 \pm 74.4$ & 0.685 \\
Anaerobik güç $(\mathrm{kg}-\mathrm{m} / \mathrm{s})$ & $52.3 \pm 12.1$ & $55.1 \pm 12.4$ & 0.361 \\
\hline *: $p<0.05$ & $39.2 \pm 7.3$ & $46.8 \pm 9.7$ & $\mathbf{0 . 0 0 1 *}$ \\
\hline
\end{tabular}

Tablo 3. 12 yaș Türk badmintoncuların antropometrik ve motorik performans özellikleri

\begin{tabular}{|c|c|c|c|}
\hline Parametreler & Erkek $(n=53)$ & Kız (n=33) & $\mathbf{p}$ \\
\hline Boy uzunluğu (cm) & $147.6 \pm 6.4$ & $148.9 \pm 6.5$ & 0.352 \\
\hline Kulaç uzunluğu (cm) & $148.5 \pm 7.1$ & $150.1 \pm 7.2$ & 0.300 \\
\hline Vücut ağırlığı (kg) & $38.7 \pm 5.3$ & $39.9 \pm 7.6$ & 0.384 \\
\hline BKİ $\left(\mathrm{kg} / \mathrm{boy}^{2}\right)$ & $17.8 \pm 2.0$ & $17.9 \pm 2.5$ & 0.965 \\
\hline 20 m sürat (s) & $3.85 \pm 0.21$ & $4.16 \pm 0.29$ & 0.001* \\
\hline Durarak uzun atlama $(\mathrm{cm})$ & $150.8 \pm 17.6$ & $139.2 \pm 19.3$ & $0.005^{*}$ \\
\hline Dikey sıçrama (cm) & $30.0 \pm 4.6$ & $26.4 \pm 4.0$ & $0.001 *$ \\
\hline Esneklik (cm) & $-1.19 \pm 7.68$ & $0.64 \pm 8.89$ & 0.317 \\
\hline Sağlık topu atma (cm) & $448.4 \pm 71.6$ & $375.4 \pm 65.7$ & $0.001 *$ \\
\hline Sirt kuvveti (kg) & $62.7 \pm 12.2$ & $51.5 \pm 13.2$ & 0.001* \\
\hline Anaerobik güç (kg-m/sn) & $46.7 \pm 7.1$ & $45.3 \pm 9.2$ & 0.398 \\
\hline
\end{tabular}

*: $p<0.05$

Tablo 4.13 yaş Türk badmintoncuların antropometrik ve motorik performans özellikleri

\begin{tabular}{|c|c|c|c|}
\hline Parametreler & Erkek $(n=30)$ & $\mathbf{K 1 z}(\mathrm{n}=34)$ & $\mathbf{p}$ \\
\hline Boy uzunluğu (cm) & $157.1 \pm 7.8$ & $155.8 \pm 7.2$ & 0.479 \\
\hline Kulaç uzunluğu (cm) & $159.1 \pm 9.0$ & $156.9 \pm 8.2$ & 0.306 \\
\hline Vücut ağırlığı (kg) & $47.1 \pm 7.4$ & $47.2 \pm 8.9$ & 0.972 \\
\hline BKİ $\left(\mathrm{kg} / \mathrm{boy}^{2}\right)$ & $19.0 \pm 1.7$ & $19.3 \pm 2.9$ & 0.570 \\
\hline 20 m sürat $(s)$ & $3.74 \pm 0.24$ & $4.03 \pm 0.28$ & $0.001 *$ \\
\hline Durarak uzun atlama $(\mathrm{cm})$ & $146.8 \pm 21.5$ & $135.5 \pm 13.6$ & $0.017 *$ \\
\hline Dikey sıçrama (cm) & $32.0 \pm 5.4$ & $27.9 \pm 4.6$ & $0.002 *$ \\
\hline Esneklik $(\mathrm{cm})$ & $-1.57 \pm 8.47$ & $3.97 \pm 8.34$ & $0.011^{*}$ \\
\hline Sağlık topu atma $(\mathrm{cm})$ & $530.6 \pm 122.8$ & $444.3 \pm 106.6$ & $0.004^{*}$ \\
\hline Sirt kuvveti (kg) & $72.3 \pm 20.5$ & $60.8 \pm 14.4$ & $0.013 *$ \\
\hline Anaerobik güç (kg-m/s) & $59.1 \pm 12.0$ & $55.0 \pm 10.7$ & 0.150 \\
\hline
\end{tabular}


Tablo 5.14 yaş Türk badmintoncuların antropometrik ve motorik performans özellikleri

\begin{tabular}{llll}
\hline Parametreler & Erkek $(\mathrm{n}=26)$ & Kız $(\mathrm{n}=25)$ & $\mathbf{p}$ \\
\hline Boy uzunluğu $(\mathrm{cm})$ & $158.2 \pm 8.1$ & $156.2 \pm 7.0$ & 0.360 \\
\hline Kulaç uzunluğu $(\mathrm{cm})$ & $161.6 \pm 10.1$ & $158.8 \pm 6.6$ & 0.256 \\
\hline Vücut ağırlığı $(\mathrm{kg})$ & $48.3 \pm 7.4$ & $52.3 \pm 10.1$ & 0.114 \\
\hline BKì $\left(\mathrm{kg} / \mathrm{boy}^{2}\right)$ & $19.2 \pm 1.6$ & $21.4 \pm 3.6$ & $\mathbf{0 . 0 0 8}$ \\
\hline 20 m sürat $(\mathrm{s})$ & $3.69 \pm 0.26$ & $4.05 \pm 0.31$ & $\mathbf{0 . 0 0 1}$ \\
\hline Durarak uzun atlama $(\mathrm{cm})$ & $154.5 \pm 21.2$ & $135.3 \pm 10.9$ & $\mathbf{0 . 0 0 1}$ \\
\hline Dikey sıçrama $(\mathrm{cm})$ & $33.3 \pm 6.7$ & $26.7 \pm 4.0$ & $\mathbf{0 . 0 0 1}$ \\
Esneklik $(\mathrm{cm})$ & $2.85 \pm 9.29$ & $6.44 \pm 6.19$ & 0.112 \\
Sağlık topu atma $(\mathrm{cm})$ & $568.5 \pm 140.4$ & $462.1 \pm 95.2$ & $\mathbf{0 . 0 0 3}$ \\
\hline Sirt kuvveti $(\mathrm{kg})$ & $79.5 \pm 20.4$ & $62.1 \pm 14.7$ & $\mathbf{0 . 0 0 1}$ \\
Anaerobik güç $(\mathrm{kg}-\mathrm{m} / \mathrm{s})$ & $61.6 \pm 12.7$ & $59.5 \pm 11.2$ & 0.537 \\
\hline *: $p<0.05$ & & &
\end{tabular}

\section{TARTIŞMA}

Badminton sporunda uzun boy ve kollara sahip oyuncular korttaki her bölgeye kolayca ulaşabilme bakımından oldukça avantajlıdır. $\mathrm{Bu}$ oyuncular, özellikle smaç ve drop vuruşlarında topu en yüksek noktada yakalayarak etkili vuruşlar yapabilirler $(20,21)$. Diğer bir görüşe göre boy uzunluğu badmintonda başarıyı etkileyen birçok faktörden sadece biridir ve başarının kritik bir belirleyicisi olup olmadığı net değildir (22). Ayrıca, vücut ağırlığı ve beden kütle indeksindeki fazlalık durumu kort üzerinde hızlı hareket edebilme becerisine sinırlama getirirken; çeviklik ile üst ve alt ekstremite patlayıcı gücü üzerinde olumsuz bir etkiye neden olur $(22,23)$. Hotaman, vücut ağırlı̆̆ı ile arka kort bölgesinde yapılan basit hatalar arasında pozitif yönlü anlamlı bir ilişki olduğunu bildirmiştir (24).

Bu çalışmada, 11 yaş kızların boy uzunluğu, kulaç uzunluğu, vücut ağırlığı ve beden kütle indeksi, 14 yașta ise beden kütle indeksi değerleri erkeklerden anlamlı olarak daha yüksek bulunurken $(p<0.01)$, diğer yaş gruplarında anlamlı fark görülmedi $(p>0.05)$. Bu farkın, erkek ve kızların farklı yaş dönemlerinde sahip oldukları büyüme hızı ile ilgili olduğu düşünülmektedir. Kız ve erkeklerin boy uzunlukları 11 yaşına kadar benzer görülürken, 11 yaşından itibaren kızların uzama hızı erkeklerin iki katıdır. Ancak, 13 yaşında kızların boy uzaması yavaşlarken erkeklerde hızlanma başlar $(25,26)$. Benzer şekilde, vücut ağırlığının en hızlı gelişme sürecinin kızlarda 11-13, erkeklerde ise 12-15 yaş arasında olduğu ifade edilmektedir (17). Genelde 11 yaşındaki kızlar daha ağır iken, 11 yaşından sonra kızların kilolarında azalma olur ve erkekler kızlardan kiloca fazlalaşmaya başlar $(25,26)$. Bu çalışmada, kızlarda en hızlı boy uzunluğu (11.7 cm, \%7.8), kulaç uzunluğu (12.2 $\mathrm{cm}, \% 8.9)$, vücut ağırlı̆̆ $(11.5 \mathrm{~kg}, \% 37.4)$ ve beden kütle indeksi $\left(2.86 \mathrm{~kg} / \mathrm{boy}^{2}, \% 17.6\right)$ artışı 11 yaşında görülürken, erkeklerde en hızlı boy uzunluğu $(9.5 \mathrm{~cm}, \% 6.4)$, kulaç uzunluğu $(10.6$ $\mathrm{cm}, \% 7.2)$, vücut ağırlığı (8.4 kg, \%21.4) ve beden kütle indeksi (1.23 kg/boy ${ }^{2}$, \%6.9) 13 yaşında gözlendi.

Çalışmadaki oyuncuların verileri literatür ile karşılaştırıldığında, boy uzunluğu ve vücut ağırlı̆̆ değerleri Amerika Birleşik Devletleri Spor Akademisi IPF test norm değerleri (18) ve atletizm yetenek taraması normatif değerlerinden (27) yüksek, kulaç uzunluğu verileri ise Türk çocuklarının fiziki uygunluk norm verileri ile benzer bulundu (17).

Badminton müsabakalarında topa etkili ve isabetli vuruşlar uygulayabilmek için kortta doğru ve erken pozisyon almak esastır. Bu da bacak ve ayakların hızlı ve çabuk bir şekilde hareket etme yeteneğine bağlıdır (28). Badmintonda hızlı koşu, ani duruş ve başlangıçlar, sıçramalar, hızlı 
yön değiștirmeler iyi bir performans elde etmede son derece önemlidir (29). Çalışmadaki erkeklerin sürat değerleri tüm yaş gruplarında kızlardan anlamlı olarak yüksek bulundu $(\mathrm{p}<0.01)$. Erkeklerde en hızlı sürat artışı 12 (0.21 s, \%5.2), kızlarda ise 11 yaşında $(0.13 \mathrm{~s}$, \%3.2) gözlendi. Araştırmalar maksimal sürat gelişiminin 12-15 yaş arasında olduğunu ve 18 yaşına kadar erkek çocukların maksimal sürat değerlerinin artış gösterdiğini vurgulamaktadır $(17,30,31)$. Çalışmadaki erkeklerin sürat değerleri atletizme yönelik standart norm verileri (27) ve IPPTP test norm değerlerinden (18) yüksek saptandı. Kızların verileri ise atletizme yönelik standart norm değerlerinden yüksek çıkarken (27), IPPTP test norm değerlerinden düşüktü.

Badminton küçük bir oyun alanı üzerinde, çok hızlı hareket etmeyi gerektiren, benzersiz bir hareket tekniği içeren yüksek seviyede patlayıcı bir spordur (32). Hem alt hem de üst ekstremite kaslarının patlayıcılık özellikleri badminton branşı için son derece önemlidir (22). Badmintoncuların alt ekstremite patlayıcı kuvvet değerlerinde meydana gelen artış ile müsabaka sırasında yaptıkları basit hatalarda azalma olduğu belirtilmiştir (24). Bu çalışmadaki erkeklerin durarak uzun atlama değerleri tüm yaş gruplarında kızlardan anlamlı olarak yüksek bulundu $(p<0.05)$. Dikey sıçrama verileri 11 yaş grubunda benzer görülürken ( $p>0.05)$, diğer yaş gruplarında erkekler lehine anlamlı fark vardı $(p<0.05)$. Çocuklar için sıçrama özelliğinin en yoğun gelişme evresi 11-12 yaş döneminde bulunmuştur (17).

Çalışmamızda kızlarda $(10.6 \mathrm{~cm}, \% 8.3)$ ve erkeklerde $(11.4 \mathrm{~cm}, \% 8.2)$ en hızlı durarak uzun atlama gelişimi 12 yaşında gözlendi. Dikey sıçrama sonuçları incelendiğinde, kızlardaki en hızlı artış 11 yaşında $(2.0 \mathrm{~cm}, \% 8.4)$ görülürken, erkeklerde 13 yaşında $(3.8 \mathrm{~cm}, \% 14.1)$ saptandı. Çalışmadaki durarak uzun atlama sonuçları literatür ile karşılaştırıldığında, atletizm yetenek taraması normatif değerlerinden yüksek (27), IPPTP test normları (18) ve Türk çocuklarının fiziki uygunluk norm verilerinden (17) düşük bulundu. Dikey sıçrama verileri kıyaslandığında, yıldız erkek milli ve amatör badmintoncuların verileriyle benzer (10), 14-16 yaș Türkiye, Avusturya, Belçika ve Macaristan milli takım badminton sporcularının değerlerinden düşük değerler elde edildi (13).

Her iki cinste sağlık topu atma sonuçları 10 ve 11 yaşta benzerken ( $p>0.05) ; 12,13$ ve 14 yaş gruplarında erkekler lehine anlamlı fark saptandı $(\mathrm{p}<0.01)$. Sağlık topu atma değerlerindeki en hızlı artış, kızlarda 11 (78.9 cm, \%26.1), erkeklerde 13 yaşında $(82.2 \mathrm{~cm}, \% 18.3)$ gözlendi. Değerler Brezilya genç milli badminton oyuncularının düzeylerinden düşüktü (3).

Esnekliğin uygun düzeyleri, oyunculara çeșitli vuruşları etkili bir şekilde gerçekleştirebilme imkanı sağlar. Omurga ve omuz eklemleri ile kalça ve topuk kirişlerinin esneklik seviyelerinin iyi olması, file bölgesine yapılan hamlelerde daha düzgün ve isabetli vuruşlara izin verir (25). $\mathrm{Bu}$ çalışmada, 10 yaşta erkeklerin değerleri kızlardan anlamlı olarak yüksek çıkarken $(\mathrm{p}<0.05), 11$ ve 13 yaş grubunda kızların değerleri anlamlı olarak daha yüksek bulundu $(p<0.05)$. Kızlarda esneklik niteliğinin maksimal gelişimi 11-13 yaşları arasında iken, erkeklerde 13-15 yaşları arasında olmaktadır (25). Çalışmada esnekliğin en hızlı artışı kızlarda 13, erkeklerde 14 yaşında gözlendi. Araştırmamızdaki badmintoncuların esneklik verileri Türk çocuklarının esneklik değerleri ile benzerlik göstermektedir (17).

Karın ve sirt kasları badminton sporunda kullanılan tüm hareketlerde önemli derecede rol oynar. Bu kaslar tüm durdurma ve harekete geçirme hareketleri için önemli bir dengeleme ve sağlamlaştırma ve işlevini gerçekleştirir (8). Bu çalışmadaki kız ve erkeklerin sırt kuvveti değerleri 11 yaşında benzerken ( $p>0.05)$, diğer tüm yaşlarda erkeklerin değerleri anlamlı olarak yüksek bulundu $(\mathrm{p}<0.05)$. Cinsiyet farklarının 10-11 yaşından itibaren gözlenmesiyle hızlanan kuvvet gelişimi, 13-14 yaşlarında büyük bir fark oluşturur (25). Sırt kuvvetindeki en hızlı artış kızlarda 11 (15.7 kg, \%39.8), erkeklerde 12 yaşında (10.5 kg, \%20.0) gerçekleşti. Erkek ve kızlarda en yüksek sırt kuvveti değerleri 14 yaşında saptandı. Erkeklerin sırt kuvveti verileri literatüre göre yüksek iken, kızların verileri dü- 
şük bulundu (17). Bu sonuçlar kızların spesifik kuvvet çalışmalarına daha fazla önem vermeleri gerektiğini göstermektedir.

Yüksek bir anaerobik gücün varlığı oyunculara maç temposunu hızlı tutma ve uzun süren şiddetli müsabakaları daha rahat olarak devam ettirme olanağı sağlar (22). Çalışmamızdaki kızların anaerobik güç değerleri 11 yaş grubunda anlamlı olarak yüksek iken $(p<0.05)$, diğer tüm yaş gruplarında kız ve erkeklerin değerleri benzer bulundu ( $p>0.05)$. En hızlı anaerobik güç artışı kızlarda 11 (13.7 kg-m/sn, \%41.2), erkeklerde 13 yaşında (12.4 kg-m/sn, \%26.4) gözlendi. U17 Türk ve yabancı milli badmintoncuların anaerobik güç değerleri erkek Türk sporcularda $102.6 \pm 16.2$, yabancılarda $106.3 \pm 10.5$, kızların değerleri ise Türk sporcularda $79.2 \pm 8.9$, yabancilarda $79.8 \pm 11.8 \mathrm{~kg}-\mathrm{m} / \mathrm{sn}$ olarak bildirilmiştir. Çalışmamızdaki değerlerden yüksek olan bu sonuçlar katılımcıların üst yaş grubunda ve milli sporcu olmaları ile açıklanabilir.

Sonuç olarak; bu çalışmada, kızlarda 11 yaş grubunda boy uzunluğu, kulaç uzunluğu, vücut ağırlığı ve beden kütle indeksi, esneklik ve anaerobik güç değerleri; 13 yaş grubunda esneklik, 14 yaş grubunda ise beden kütle indeksi değerleri anlamlı olarak daha yüksek iken, erkeklerin sürat, durarak uzun atlama, dikey sıçrama (11 yaş hariç), sağlık topu atma (12, 13 ve 14 yaş), sırt kuvveti (11 yaş hariç) değerleri anlamlı olarak daha yüksek bulundu. Genel olarak badmintoncuların antropometrik ve motorik performans kapasitelerinde en hızlı artışın olduğu dönem kızlarda 11 yaş olarak belirirken, erkeklerde 12-13 yaşları olarak çıktı. Özellikle bu hızlı gelişim evreleri dikkate alınarak badminton oyuncularına yönelik spesifik antrenman programlarının hazırlanması önerilmektedir. Badminton branşıyla ilgilenen antrenörler, çalışmadaki veriler ve testlerden yararlanarak sporcularının eksik yönlerini belirleyebilir ve uygun antrenman programları oluşturabilirler. Bu çalışmada reaksiyon zamanı, çabukluk, bacak kuvveti ve aerobik güç testleri gerçekleştirilmedi. Badminton branşı ile ilgili gelecek araștırmalarda bu testler de kullanılmalıdır.

\section{KAYNAKLAR}

1. MacDougall JD, Wenger HA, Green HJ. Physiological Testing of the High Performance Athlete. 2nd ed. Champaign, lL: Human Kinetics; 1991.

2. Daniels J. Physiological chacteristics of champion male athletes. Res Q. 1974;45(4):342-48.

3. Campos FAD, Daros LB, Mastrascusa V, et al. Anthropometric profile and motor performance of junior badminton players. Braz J Biomotricity. 2009;3(2):146-51.

4. Ellenbecker TS. A total arm strength isokinetic profile of highly skilled tennis players. Isokinetics Exerc Sci. 1991;1(1):9-21.

5. Phomsoupha M, Laffaye G. The science of badminton: game characteristics, anthropometry, physiology, visual fitness and biomechanics. Sports Med. 2015;45(4):473-95.

6. Bańkosz Z, Nawara H, Ociepa M. Assessment of simple reaction time in badminton players. Trends Sports Sci. 2013;20(1):54-61.

7. Coşan F. Sporda Atletik Hazırlığın Denetimi ve Değerlendirilmesinde Yenilikçi Yaklaşımlar. Razgard, Bulgaria: Polygraph Razgard Ltd; 2016.

8. Ømosegård BO, Tindholdt L. Physical Training for Badminton. Cheltenham: Malling Beck; 1996.

9. Gao RY. A Comparison between talent identification and development (TID) for Badminton in China and the UK. The University of Stirling Faculty of Health Sciences and Sport Master's Thesis. Stirling: University of Stirling; 2017.

10. Kafkas ME, Taşkıran C, Arslan C, et al. Yıldız erkek milli ve amatör badmintoncuların bazı fiziksel, fizyolojik ve antropometrik parametrelerinin karşılaştırılması. Niğde Üniversitesi BESB Dergisi. 2009;3(1):13-20.

11. Yllmaz N. Milli Takım ve mahalli liglerde oynayan badmintoncuların antropometrik özellikleri ile çabukluk, esneklik ve dayanıklılıklarının araştırılması. Dumlupınar Üniversitesi Sağlı Bilimleri Enstitüsü Beden Eğirimi ve Spor Anabilim Dalı Yüksek Lisans Tezi. Kütahya: Dumlupınar Üniversitesi; s. 19-34, 2013.

12. Güçlüöver A, Demirkan $E$, Kutlu $M$, et al. The comparison of some physical and physiological features of elite youth national and amateur badminton players. J Phys Ed Sport Sci. 2012;6(3): 244-50.

13. Poyraz A, Baş O, Ocak Y, et al. Avrupa Badminton Takım Şampiyonasına katılan sporcuların bazı fiziksel ve fizyolojik özelliklerinin karşılaştırılması. Spor ve Performans Araştırmaları Dergisi. 2015;6(2):121-33.

14. Revan S, Aydoğmuş M, Balcı ŞS, et al. Türk ve yabancı ülke milli takım badmintoncularının bazı fiziksel ve fizyolojik özelliklerinin değerlendirilmesi. Niğde Üniversitesi BESB Dergisi. 2007;1(2):66-7. 
15. Karaca F. 10-14 Yaş erkek futbolcu ve badmintoncularda bazı fiziksel fizyolojik ve biyomotorik özelliklerinin karşılaştırılması. Dumlupınar Üniversitesi Sağlı Bilimleri Enstitüsü Beden Eğirimi ve Spor Anabilim Dalı Yüksek Lisans Tezi. Kütahya: Dumlupınar Üniversitesi; 2012.

16. Saçıkara A. Raket sporcularının atletik performanslarının incelenmesi. Selçuk Üniversitesi Sağlık Bilimleri Enstitüsü Beden Eğitimi ve Spor Anabilim Dalı Yüksek Lisans Tezi. Konya: Selçuk Üniversitesi; 2018.

17. Coşan F, Demir A, Mengütay S. Türk Çocuklarının Fiziki Uygunluk Normları. İstanbul: Olimpiyat Oyunları Hazırlık ve Düzenleme Kurulu Eğitim Yayınları Yayın No 1. İstanbul; 2002.

18. Kamar A. Sporda Yetenek Beceri ve Performans Testleri. Ankara: Nobel Yayın Dağıtım; 2003.

19. Özer K. Fiziksel Uygunluk. 2. Baskı. İstanbul: Nobel Yayın Dağıtım; 2006.

20. Abdullahi Y, Toriola AL, Goon DT, et al. Anthropometric and motor performance characteristics of Nigerian badminton players. Asian J Sci Res. 2017;10(3):244-51.

21. Ooi CH, Tan A, Ahmad A, et al. Physiological characteristics of elite and sub-elite badminton players. J Sport Sci. 2009;27(14):1591-9.

22. Reilly T, Secher N, Snell P, et al. Physiology of Sports: an Overview. $1^{\text {st }}$ ed. London: E \& FN Spon; 1990.

23. Cinthuja P, Jayakody JAOA, Perera MPM, et al. Physical fitness factors of school badminton players in Kandy district. Eur J Sports Exerc Sci. 2015;4(2):14-25.

24. Hotaman F. 15-17 yaş grubu badmintoncuların müsabaka sırasında yaptıkları basit hatalar ile fiziksel ve teknik performansları arasındaki ilișikinin incelenmesi. Marmara Üniversitesi Sağlık Bilimleri Enstitüsü Beden Eğirimi ve Spor Anabilim Dalı Yüksek Lisans Tezi. İstanbul: Marmara Üniversitesi; 2019.

25. Mengütay S. Cocuklarda Hareket Gelișimi ve Spor. İstanbul: Morpa Kültür Yayınları; 2006.

26. Muratlı S. Cocuk ve Spor. 2. Baskı. Ankara: Bağırgan Yayımevi; 1997.

27. Pekel HA. Atletizmde yetenek taramasına bağlı olarak 10-12 yaş grubu çocuklarda bazı değişkenler üzerinde normatif çalışma (Ankara ili örneği). Gazi Üniversitesi Üniversitesi Sağlık Bilimleri Enstitüsü Beden Eğirimi ve Spor Anabilim Dalı Doktora Lisans Tezi. Ankara: Gazi Üniversitesi; 2007.

28. Todd MK, Mahoney CA. Determination of pre-season physiological characteristics of elite male squash players. In: Reilly T, Hughes M, Lees A, Eds. Science and Racket Sports. London: E \& FN Spon; 1994. p. 818.

29. Mahoney CA, Sharp NCC. The physiological profile of elite junior squash players. In: Reilly $\mathrm{T}$, Hughes $\mathrm{M}$, Lees A, Eds. Science and Racket Sports. London: E \& FN Spon; 1994. p. 76-80.

30. Ziyagil AM, Zorba E, Bozatlı Z, ve ark. 6-14 yaş grubu çocuklarda yaş, cinsiyet ve spor yapma alışkanlığının sürat ve anaerobik güce etkisi. CBÜ BESB Dergisi. 1999;3(3):9-18.

31. Karatosun H. Antrenmanin Fizyolojik Temelleri. Isparta: Tuğra Ofset; 2003.

32. Hughes MG. Physiological demands of training in elite badminton players. In: Reilly T, Hughes M, Lees A, editors. Science and Racket Sports. London: E \& FN Spon; 1994. p. 32-7. 